\title{
Effects of Endothelin on Peptide-dependent Cyclic Adenosine Monophosphate Accumulation along the Nephron Segments of the Rat
}

\author{
Kimio Tomita, Hiroshi Nonoguchi, and Fumiaki Marumo \\ 2nd Department of Internal Medicine, Tokyo Medical \& Dental University, Tokyo 113, Japan
}

\begin{abstract}
We investigated the tubular action of endothelin in rat nephron segments. The effects of endothelin on arginine vasopressin (AVP)-, parathyroid hormone-, glucagon-, calcitonin-, and isoproterenol-dependent CAMP accumulation were studied. The following nephron segments were microdissected: glomerulus (Gl), proximal convoluted tubule (PCT), cortical and medullary thick ascending limbs of Henle's loop (cTAL and mTAL, respectively), cortical collecting duct (CCD), outer medullary collecting duct (OMCD), and inner medullary collecting duct (IMCD). Endothelin dose dependently $\left(10^{-8}-10^{-10}\right.$ M) inhibited AVP-dependent cAMP accumulation in CCD, OMCD, and IMCD. This effect was independent of the presence or absence of phosphodiesterase inhibitor, 3-isobutyl-1methylxanthine, Ca channel blocker nicardipine, or indomethacin, but was abolished in the presence of protein kinase $C$ inhibitor H-7. Protein kinase $\mathrm{C}$ stimulator dioctanoyl glycerol mimicked the effect of endothelin. On the other hand, endothelin had no inhibitory effect on AVP-dependent cAMP accumulation in cTAL or mTAL, parathyroid hormone-dependent cAMP accumulation in Gl and PCT, or glucagon-, calcitonin-, and isoprotererol-dependent cAMP accumulation in OMCD.

We conclude that endothelin specifically inhibits AVP-dependent CAMP accumulation in CCD, OMCD, and IMCD through activating protein kinase $C$. This effect possibly has a role in maintaining urine volume to counteract the decrease in GFR caused by endothelin itself. (J. Clin. Invest. 1990. 85:2014-2018.) arginine vasopressin $\bullet$ protein kinase $C \cdot \mathrm{mi}-$ crodissection $\cdot$ collecting duct $\bullet$ diuresis
\end{abstract}

\section{Introduction}

Endothelin is a new peptide and has potent vasoconstrictor activity, mediated by $\mathrm{Ca}$ entry through a plasma membrane $\mathrm{Ca}$ channel (1). Immunoreactive endothelin was detected in plasma of humans (2), suggesting that endothelin has a potential role as a circulating hormone. In the isolated perfused rat kidney, endothelin decreased the GFR, while the same dose of

Address reprint requests to Dr. Kimio Tomita, 2nd Department of Internal Medicine, Tokyo Medical \& Dental University, Yushima 1chome, Bunkyo-ku, Tokyo 113, Japan.

Received for publication 6 October 1989 and in revised form 23 January 1990.

J. Clin. Invest.

(c) The American Society for Clinical Investigation, Inc.

0021-9738/90/06/2014/05 \$2.00

Volume 85, June 1990, 2014-2018 angiotensin II had little effect on GFR (3). A recent report showed that the urinary flow rate increased after endothelin administration in the anesthetized rat, even though GFR and renal plasma flow significantly decreased, by $\sim 50 \%$ (4). Another work indicated that endothelin decreased urinary sodium excretion, urine osmolality, and osmolar clearance, and that it increased free water clearance (5). Recent autoradiographic study indicated the presence of binding sites for endothelin in medulla as well as glomerulus of the rat kidney (6). These observations suggest that endothelin may have target sites in the kidney other than the glomerulus, possibly on renal tubules.

Three possibilities can be considered if endothelin has a diuretic action on renal tubules. The first possibility is the direct stimulation or inhibition of epithelial transport. A second is stimulation of other factors that have diuretic action on tubules, such as bradykinin, prostaglandins, and atrial natriuretic factor. A third is inhibition of the action of hormones that have antidiuretic action on tubules, such as vasopressin (AVP), catecholamines, and mineralocorticoid. AVP is the most important of the above mentioned factors. Therefore, our investigation is mainly focused on the interaction between AVP and endothelin in the distal segments where urine can be maximally concentrated. In addition, the effects of several peptides such as PTH, glucagon, calcitonin, and isoproterenol were also investigated to see the specificity and sites of the action of endothelin.

\section{Methods}

Endothelin, PTH, and salmon calcitonin were purchased from Peptide Institute, Osaka, Japan. Endothelin was dissolved with $0.001 \%$ Triton $\mathrm{X}-100$. AVP, glucagon, isoproterenol, 3-isobutyl-1-methylxanthine (IBMX), ${ }^{1}$ indomethacin, 1,2-dioctanoyl-sn-glycerol, TCA, and BSA were obtained from Sigma Chemical Co. (St. Louis, MO). Protein kinase $\mathrm{C}$ inhibitor $\mathrm{H}-7,1$-(5-isoquinolinesulfonyl)-2-methylpiperazine dihydrochloride was purchased from Seikagaku Kogyo Co., Ltd. (Tokyo, Japan). Nicardipine was a kind gift from Yamanouchi Pharmaceutical Ltd. (Tokyo, Japan). All other chemicals were of first grade purity.

Solutions. The microdissection solution (solution 1) was a Hepesbuffered solution of the following concentration (in millimolar): 130 $\mathrm{NaCl}, 5 \mathrm{KCl}, 1 \mathrm{NaH}_{2} \mathrm{PO}_{4}, 1 \mathrm{MgSO}_{4}, 1 \mathrm{Ca}$ lactate, $2 \mathrm{Na}$ acetate, 5.5 glucose, $5 \mathrm{~L}$-alanine, $2 \mathrm{~L}$-leucine, and 10 Hepes, and 0.05\% BSA was

1. Abbreviations used in this paper: ANP, atrial natriuretic peptide; CCD, cortical collecting duct; cTAL, cortical thick ascending limb of Henle's loop; Gl, glomerulus; IBMX, 3-isobutyl-1-methylxanthine; IMCD, inner medullary collecting duct; mTAL, medullary thick ascending limb of Henle's loop; OMCD, outer medullary collecting duct; PCT, proximal convoluted tubule; RBF, renal blood flow. 
added after $\mathrm{pH}$ adjustment to 7.4 by $\mathrm{NaOH}$. The collagenase solution (solution 2) was of the same composition as the microdissection solution, except it contained $0.1 \%$ BSA and $0.1 \%$ collagenase.

Isolation of nephron segments. Microdissection was done as previously described $(7,8)$ with a slight modification. Male SpragueDawley rats $(120-170 \mathrm{~g})$ were anesthetized with pentobarbital sodium $(50 \mathrm{mg} / \mathrm{kg}$ i.p.). The left kidney was perfused in situ with $10 \mathrm{ml}$ of solution 2 after clamping the thoracic aorta and right renal artery. The kidney was removed and $1-\mathrm{mm}$-thick slices were suspended in $15 \mathrm{ml}$ of solution 2. They were incubated for $40 \mathrm{~min}$ at $37^{\circ} \mathrm{C}$ while $100 \% \mathrm{O}_{2}$ was bubbled through the solution. The slices were then washed with solution 1 and transferred to an ice-cold petri dish that was kept at $4^{\circ} \mathrm{C}$ by a cooling plate. Nephron segments were dissected under a dissecting microscope (Olympus, Tokyo, Japan). The isolated structures were glomerulus ( $\mathrm{Gl}$ ), proximal convoluted tubule (PCT), cortical thick ascending limb of Henle's loop (cTAL), medullary thick ascending limb of Henle's loop (mTAL), cortical collecting duct (CCD), inner stripe of outer medullary collecting duct (OMCD), and middle third of the inner medullary collecting duct (IMCD). IMCD were dissected from carefully localized positions along the inner medullary axis (9). The total length of tubules was determined with an eyepiece micrometer. Microdissected tubules were transferred with $2 \mu$ lof solution 1 using a siliconized glass pipette into $1.5-\mathrm{ml}$ plastic centrifuge tubes containing $18 \mu \mathrm{l}$ of solution 1 with an appropriate concentration of IBMX.

Assay procedure of cAMP. Microdissected segments in $20 \mu \mathrm{l}$ were preincubated with $10 \mu \mathrm{l}$ of an appropriate concentration of endothelin and/or nicardipine, dioctanoyl glycerol, and $\mathrm{H}-7$ for $10 \mathrm{~min}$, indomethacin for $30 \mathrm{~min}$ at $37^{\circ} \mathrm{C}$. After preincubation, $10 \mu \mathrm{l}$ of an appropriate concentration of peptides in solution 1 with or without IBMX was added. The incubation was terminated after 3-10 min by the addition of $50 \mu \mathrm{l}$ of ice-cold $10 \%$ TCA with complete mixing. Each tube was centrifuged for $5 \mathrm{~min}$ at $3,000 \mathrm{rpm}$. A 70- $\mu \mathrm{l}$ sample from the supernatant was stored at $-40^{\circ} \mathrm{C}$ until the measurement of cAMP content. In each experiment, blank samples (containing medium and TCA without tubules) were also processed for cAMP standards. Frozen samples were thawed at room temperature and the TCA was removed by extraction four times with $1.0 \mathrm{ml}$ of water-saturated ether. After evaporation of the ether, the remaining aqueous phase was dried using a vacuum drying oven (model DPA-30; Yamato Scientific Co., Ltd., Tokyo, Japan) and $100 \mu \mathrm{l}$ of $50 \mathrm{mM}$ sodium acetate buffer (pH 6.2) was added to each sample. Appropriate cAMP standards were added to blank samples. Samples of unknowns and cAMP standards were then assayed for cAMP content (radioimmunoassay kits; New England Nuclear, Boston, MA). The values of cAMP content were expressed per glomerulus or millimeter per 3 or $10 \mathrm{~min}$. Although we used a very low concentration of Triton X-100 to dilute endothelin, Triton X-100 was further diluted according to the dilution of endothelin. At $0.000001 \%$ Triton X-100 does not affect the cAMP production stimulated by AVP. Each point is the mean value of two to three tubes.

Statistics. The results were given as means $\pm \mathrm{SE}$. The differences were tested using analysis of variance or $t$ test. $P<0.05$ was considered significant.

\section{Results}

\section{Effects of endothelin on AVP-dependent cAMP} accumulation in rat distal nephron segments

Effects of IBMX in OMCD. cAMP accumulation was about one-tenth in the absence of IBMX, compared with values obtained in the presence of 0.5 or $2.0 \mathrm{mM}$ IBMX. AVP-dependent cAMP accumulation was similar in the presence of 0.5 and $2.0 \mathrm{mM}$ IBMX. The effect of IBMX to inhibit phosphodiesterase in rat OMCD seems maximal at a concentration of $0.5 \mathrm{mM}$ (Fig. 1). Endothelin $\left(10^{-8} \mathrm{M}\right)$ inhibited AVP-dependent cAMP accumulation in both the presence and absence of IBMX: $55.4 \%$ in the absence of IBMX, $60.0 \%$ in the presence

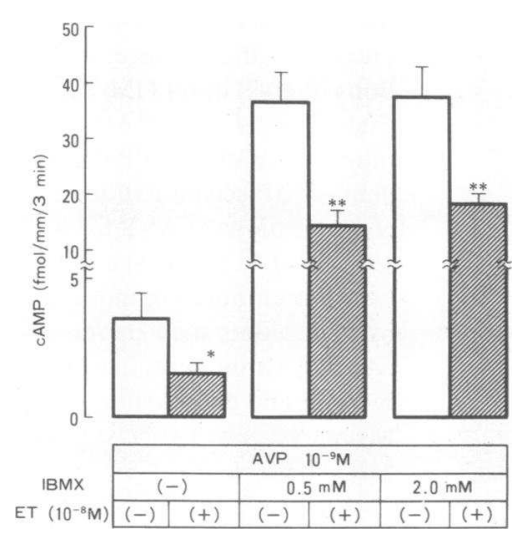

Figure 1. Effect of endothelin on AVP-dependent CAMP accumulation in the presence or absence of IBMX in rat OMCD. The effect of IBMX on inhibition of phosphodiesterase is near maximum at a concentration of $0.5 \mathrm{mM}$. Endothelin $\left(E T, 10^{-8} \mathrm{M}\right)$ significantly inhibits AVP $\left(10^{-9} \mathrm{M}\right)$-dependent cAMP accumulation at similar rates irrespective of the concentration of IBMX. Open bars, cAMP accumulation induced by AVP alone; hatched bars, cAMP accumulation induced by AVP and endothelin. Mean \pm SE, $n=4 .{ }^{*} P<0.05 ;{ }^{* *} P<0.01$.

of $0.5 \mathrm{mM}$ IBMX, and $51.1 \%$ in the presence of $2.0 \mathrm{mM}$ IBMX. This result shows that the effect of endothelin on AVP-dependent cAMP accumulation is independent of phosphodiesterase. Therefore, the following experiments were done in the presence of $0.5 \mathrm{mM}$ IBMX.

Time course in $O M C D$. Endothelin $\left(10^{-8} \mathrm{M}\right)$ significantly reduced $10^{-9} \mathrm{M}$ AVP-dependent cAMP production at all incubation times studied, from 1 to 10 min (Fig. 2).

Effects of endothelin on cAMP accumulation induced by various concentrations of $A V P$ in OMCD. cAMP production by AVP reached a plateau at a concentration of $10^{-9} \mathrm{M}$ (Fig. 3). The effect of endothelin became apparent at AVP concentrations from $10^{-10}$ to $10^{-7} \mathrm{M}$. Endothelin $\left(10^{-8} \mathrm{M}\right)$ decreased cAMP production by $60 \%$, from $36.8 \pm 5.1$ to $14.8 \pm 2.6 \mathrm{fmol} /$ $\mathrm{mm}$ per $3 \mathrm{~min}(n=6$, mean $\pm \mathrm{SE}, P<0.01)$, at a concentration of $10^{-9} \mathrm{M}$ AVP. At higher concentrations of AVP, the decrease in cAMP production by endothelin was $\sim 30 \%$. Therefore, we used $10^{-9} \mathrm{M}$ AVP for further experiments.

Effect of various concentrations of endothelin at the fixed concentration of $A V P\left(10^{-9} \mathrm{M}\right)$ in $C C D, O M C D$, and IMCD. Although the presence of endothelin binding was not shown in CCD by autoradiographic study (6), we investigated the effect of endothelin on AVP-dependent cAMP accumulation along the collecting duct, namely, CCD, OMCD, and IMCD (Fig. 4). Endothelin dose dependently inhibited AVP-dependent cAMP accumulation in CCD from $65.5 \pm 4.4$ to $43.5 \pm 2.8(P$ $<0.001)$ and $31.3 \pm 2.9 \mathrm{fmol} / \mathrm{mm}$ per $3 \mathrm{~min}(n=6, P<0.001)$ 




Figure 3. Effect of endothelin on cAMP accumulation induced by various concentrations of $A V P$ in rat $O M C D$. Endothelin $\left(E T, 10^{-8} \mathrm{M}\right)$ significantly inhibits AVP-dependent cAMP accumulation at concentrations of AVP from $10^{-10}$ to $10^{-7} \mathrm{M}$. Open circles, cAMP accumulation induced by AVP alone; solid circles, cAMP accumulation induced by AVP and endothelin. Mean \pm SE, $n=3-6 * P<0.05$; $* * P<0.01$

at concentrations of $10^{-10}$ and $10^{-8} \mathrm{M}$, respectively. Similarly, in OMCD AVP-dependent cAMP accumulation decreased from $36.8 \pm 5.1$ to $21.2 \pm 3.2$ and $14.8 \pm 2.6 \mathrm{fmol} / \mathrm{mm}$ per $3 \mathrm{~min}$ ( $n=6, P<0.01)$ at concentrations of $10^{-10}$ and $10^{-8} \mathrm{M}$ endothelin. AVP $\left(10^{-9} \mathrm{M}\right)$-stimulated cAMP production was about sixfold higher in IMCD compared with OMCD. cAMP production decreased by $23 \%$, from $238.0 \pm 8.6$ to $181.8 \pm 15.4$ $\mathrm{fmol} / \mathrm{mm}$ per $3 \mathrm{~min}(n=6$, mean $\pm \mathrm{SE}, P<0.001)$ with $10^{-9} \mathrm{M}$ endothelin. With $10^{-8} \mathrm{M}$ of endothelin, cAMP production decreased by $56 \%$.

Effect of Ca channel blocker nicardipine and indomethacin in $O M C D$. The effect of $\mathrm{Ca}$ channel blocker nicardipine was studied to investigate the mechanism of endothelin-induced inhibition of AVP-dependent cAMP accumulation (Fig. 5, left). Nicardipine enhanced AVP-dependent cAMP accumulation from $41.2 \pm 2.5(n=9)$ to $52.5 \pm 4.2(n=6, P<0.02)$ and $56.6 \pm 3.4 \mathrm{fmol} / \mathrm{mm}$ per $3 \mathrm{~min}(n=8, P<0.01)$ at concentrations of $10^{-8}$ and $10^{-6} \mathrm{M}$, respectively. This effect is consistent with a previous report (14). Endothelin similarly inhibited AVP-dependent cAMP accumulation from the above values to $18.9 \pm 1.0(n=6)$ and $16.8 \pm 0.9 \mathrm{fmol} / \mathrm{mm}$ per $3 \mathrm{~min}(n=10)$ in the presence of $10^{-8}$ and $10^{-6} \mathrm{M}$ nicardipine, respectively. AVP did not induce cAMP accumulation with complete deletion of extracellular $\mathrm{Ca}$ by $\mathrm{Ca}$-free solution containing $3 \mathrm{mM}$ EGTA (data not shown).

Next, we studied the effect of indomethacin to see whether cyclooxygenase products, such as $\mathrm{PGE}_{2}$, mediate the inhibitory action of endothelin (Fig. 5, right). Endothelin had a simi-

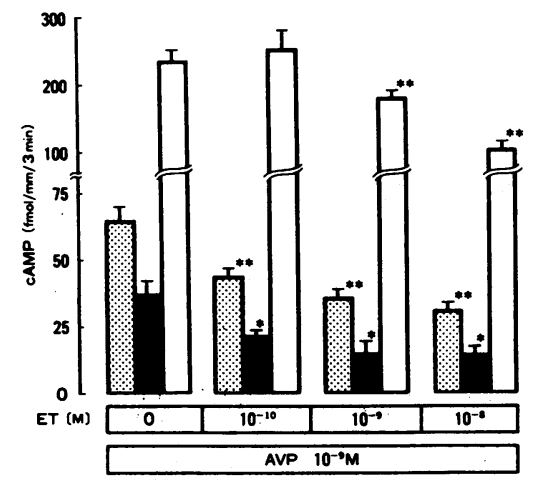

Figure 4. Effect of various concentrations of endothelin on AVP-dependent cAMP accumulation in rat collecting duct. AVP concentration was fixed at $10^{-9}$ $M$. Endothelin ( $E T$, $10^{-10}-10^{-8} \mathrm{M}$ ) significantly and dose dependently inhibited AVPdependent cAMP accumulation. Stippled bars, CCD; solid bars, OMCD; open bars, IMCD. Mean \pm SE, $n=6$. ${ }^{*} P<0.01 ;{ }^{* *} P<0.001$.
Figure 5. Effect of Ca channel blocker nicardipine and indomethacin on endothelin-induced inhibition of AVP-dependent CAMP accumulation in OMCD. Nicardipine at concentrations of $10^{-8}$ and $10^{-6} \mathrm{M}$ did not alter the inhibitory effect of endothelin on AVP-dependent CAMP accumulation (left). Indomethacin (Ind)) did not alter the inhibitory effect of endothelin (right). Mean \pm SE, $n=6-10$. ${ }^{*} P<0.02 ;{ }^{* *} P<0.01$.

lar inhibitory effect on AVP-dependent cAMP accumulation, from 40.0 $\pm 3.6(n=6)$ to $19.1 \pm 1.6(n=6, P<0.001)$ and $18.0 \pm 1.6 \mathrm{fmol} / \mathrm{mm}$ per $3 \mathrm{~min}(n=6, P<0.001)$ in the presence of $5 \times 10^{-7}$ and $5 \times 10^{-6} \mathrm{M}$ indomethacin, respectively.

Effect of protein kinase $C$ inhibitor $\mathrm{H}-7,1-(5-i$ soquinolinesulfonyl)-2-methylpiperazine dihydrochloride, and dioctanoyl glycerol on $O M C D$. The effects of inhibition or activation of protein kinase $\mathrm{C}$ were investigated using $\mathrm{H}-7$ and dioctanoyl glycerol. Protein kinase $\mathrm{C}$ inhibitor $\mathrm{H}-7$ itself does not affect either basal or AVP-dependent cAMP accumulation (Fig. 6, left). AVP-dependent cAMP accumulation decreased from $40.7 \pm 2.1(n=6)$ to $19.6 \pm 2.4 \mathrm{fmol} / \mathrm{mm}$ per $3 \min (P<0.001)$ by endothelin $\left(10^{-8} \mathrm{M}\right)$ in the absence of $\mathrm{H}-7$. However, AVPdependent cAMP accumulation reversed almost to control values, to $34.4 \pm 4.4,35.8 \pm 6.2$, and $33.9 \pm 3.4 \mathrm{fmol} / \mathrm{mm}$ per 3 $\mathrm{min}$ in the presence of protein kinase $\mathrm{C}$ inhibitor $\mathrm{H}-7$ at concentrations of $10^{-4}, 2.5 \times 10^{-5}$, and $10^{-5} \mathrm{M}$, respectively. At
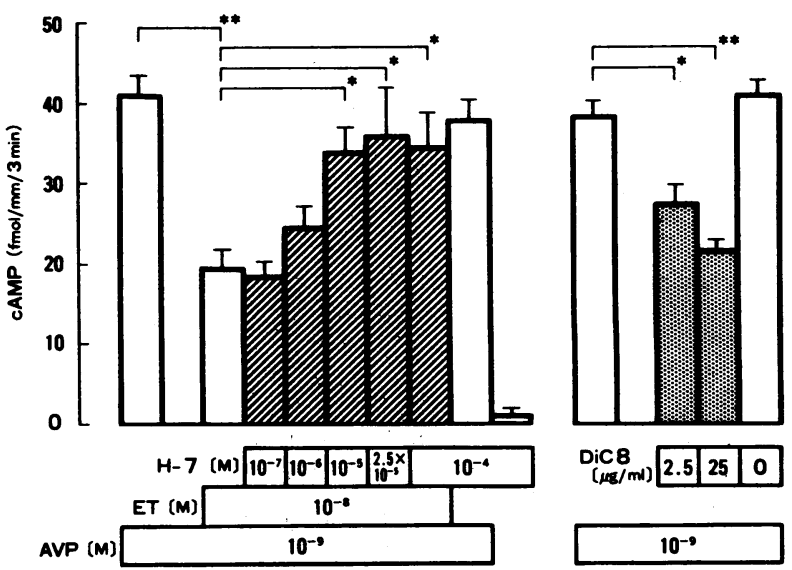

Figure 6. Effect of protein kinase $\mathrm{C}$ inhibitor $\mathrm{H}-7$ and protein kinase $\mathrm{C}$ activator dioctanoyl glycerol on the AVP-dependent cAMP accumulation in OMCD. Protein kinase $\mathrm{C}$ inhibitor $\mathrm{H}-7$ ( $H-7)$ abolished the inhibitory effect of endothelin on AVP-dependent cAMP accumulation in OMCD (left). Protein kinase $\mathrm{C}$ activator dioctanoyl glycerol (DiC8) mimicked the effect of endothelin. DMSO control (DiC8:0) had no effect on AVP-dependent cAMP accumulation. Mean \pm SE, $n=6$. ${ }^{*} P<0.01 ;{ }^{* *} P<0.001$. 
lower concentrations of $\mathrm{H}-7$, effects of $\mathrm{H}-7$ were partial $\left(10^{-6}\right.$ M) or lost $\left(10^{-7} \mathrm{M}\right)$.

The effect of protein kinase $\mathrm{C}$ activation by dioctanoyl glycerol is shown in Fig. 6 (right). Dioctanoyl glycerol mimicked the inhibitory effect of endothelin on AVP-dependent cAMP accumulation, from $38.8 \pm 2.1(n=6)$ to $27.8 \pm 2.3(P$ $<0.01)$ and $21.5 \pm 1.5 \mathrm{fmol} / \mathrm{mm}$ per $3 \mathrm{~min}(P<0.001)$ at concentrations of 2.5 and $25 \mu \mathrm{g} / \mathrm{ml}$, respectively.

Effect of endothelin in $c T A L$ and $m T A L$. CAMP production is small in cTAL and mTAL compared with CCD, OMCD, or IMCD. Endothelin $\left(10^{-8} \mathrm{M}\right)$ had no significant effect on $10^{-9}$ $M$ AVP-dependent cAMP accumulation in cTAL (from $5.7 \pm 0.6[n=6]$ to $5.9 \pm 0.3 \mathrm{fmol} / \mathrm{mm}$ per $3 \mathrm{~min}$ ) or mTAL (from 13.3 $\pm 2.0[n=6]$ to $9.7 \pm 2.0 \mathrm{fmol} / \mathrm{mm}$ per $3 \mathrm{~min}$ ).

Effects of endothelin on PTH-, glucagon-, calcitonin-, and isoproterenol-dependent cAMP accumulation

Effect of endothelin on PTH-dependent CAMP accumulation in $G l$ and PCT. Endothelin $\left(10^{-8} \mathrm{M}\right)$ had no effect on PTH-dependent cAMP accumulation in $\mathrm{Gl}$, where binding of endothelin was shown in an autoradiographic study (6) (from $18.7 \pm 1.8$ to $19.6 \pm 1.3 \mathrm{fmol} / \mathrm{Gl}$ per $3 \mathrm{~min}[n=6]$ and from $10.3 \pm 1.1$ to $10.7 \pm 1.1 \mathrm{fmol} / \mathrm{Gl}$ per $3 \mathrm{~min}$ at $10^{-7}$ and $10^{-8} \mathrm{M}$ of PTH, respectively). The effect of endothelin was also studied in PCT, where the main target segment of PTH is located. However, endothelin $\left(10^{-8} \mathrm{M}\right)$ had no effect on PTH-dependent cAMP accumulation in PCT (from 26.4 \pm 2.2 to $29.0 \pm 2.1$ $\mathrm{fmol} / \mathrm{mm}$ per $3 \mathrm{~min}[n=6$ ], and from $9.0 \pm 0.9$ to $9.2 \pm 1.2$ $\mathrm{fmol} / \mathrm{mm}$ per $3 \mathrm{~min}[n=6]$ at $10^{-6}$ and $10^{-8} \mathrm{M}$ of PTH, respectively).

Effects of endothelin on glucagon-; calcitonin-, and isoproterenol-dependent cAMP accumulation in OMCD. Endothelin $\left(10^{-8} \mathrm{M}\right)$ had no effect on glucagon-dependent cAMP accumulation in OMCD (from $7.4 \pm 1.2$ to $7.3 \pm 1.0 \mathrm{fmol} / \mathrm{mm}$ per $10 \mathrm{~min}[n=6]$, and from $2.8 \pm 0.4$ to $2.9 \pm 0.2 \mathrm{fmol} / \mathrm{mm}$ per 10 $\min [n=6]$ at $10^{-6}$ and $10^{-8} \mathrm{M}$ glucagon, respectively). Calcitonin-dependent cAMP accumulation was not affected either (from $4.6 \pm 0.9$ to $4.2 \pm 0.4 \mathrm{fmol} / \mathrm{mm}$ per $10 \mathrm{~min}$ [ $n=6$ ], and from $1.8 \pm 0.2$ to $1.9 \pm 0.1 \mathrm{fmol} / \mathrm{mm}$ per $10 \mathrm{~min}[n=6]$ at $10^{-7}$ and $10^{-8} \mathrm{M}$ calcitonin). In addition, isoproterenol-dependent cAMP accumulation was not affected (from $1.8 \pm 0.2$ to $1.7 \pm 0.2 \mathrm{fmol} / \mathrm{mm}$ per $10 \mathrm{~min}[n=6]$, and from $1.4 \pm 0.2$ to $1.2 \pm 0.2 \mathrm{fmol} / \mathrm{mm}$ per $10 \mathrm{~min}[n=6]$ at $10^{-6}$ and $10^{-8} \mathrm{M}$ isoproterenol, respectively).

\section{Discussion}

We investigated the interaction between endothelin and peptide-dependent cAMP accumulation in rat nephron segments. Our results indicated that endothelin dose dependently inhibited AVP-dependent cAMP accumulation in CCD, OMCD, and IMCD. Endothelin did not have an inhibitory effect on AVP-dependent cAMP accumulation in cTAL and mTAL. The inhibitory effect of endothelin in peptide-dependent cAMP accumulation is considered to be specific to AVP and collecting ducts because endothelin had no effect on PTH-dependent CAMP accumulation in Gl and PCT, or on glucagon-, calcitonin-, and isoproterenol-dependent cAMP accumulation in OMCD.

Several mechanisms can be considered for the inhibition of AVP-dependent cAMP accumulation by endothelin: for example, competitive inhibition of receptor, the stimulation of phosphodiesterase activity, and the inhibition of adenylate cy- clase. There are no reports so far that endothelin competitively inhibits the receptor of AVP. Therefore, this mechanism is less likely. It is not clear why endothelin inhibits AVP-dependent cAMP production less in supermaximal AVP stimulation than in maximal stimulation. A more prolonged preincubation time or a higher concentration of endothelin might be necessary to inhibit the effect of AVP in case of a supermaximal concentration of AVP. The possibility that endothelin stimulates phosphodiesterase activity is small, because the inhibitory effect of endothelin on AVP-stimulated cAMP production is independent of the presence or absence of phosphodiesterase inhibitor (IBMX) (Fig. 1). It is more likely that endothelin has an inhibitory effect on the adenylate cyclase activity. $\alpha_{2}-$ Adrenergic stimulators are also known to inhibit cAMP production in collecting ducts, probably through the activation of inhibitory $G$ protein $(8,10,11)$.

The mechanism by which endothelin inhibits adenylate cyclase activity is not known. As the mechanism of endothelin action, the increments of intracellular $\mathrm{Ca}$ are required in smooth muscle cells or cultured mesangial cells $(1,12)$. The influx of $\mathrm{Ca}$ into cytoplasma is known to inhibit the cAMP generation, possibly through the inhibition of a catalytic subunit of adenylate cyclase $(13,14)$. In our experiment, $\mathrm{Ca}$ channel blocker nicardipine had no effect on endothelin-induced inhibition of AVP-dependent cAMP accumulation. Therefore, endothelin inhibited AVP-dependent cAMP accumulation through other mechanisms than the influx of extracellular $\mathrm{Ca}$. A report suggests that endothelin inhibits $\mathrm{Na}-\mathrm{K}$ ATPase in IMCD cells of rabbits (15), possibly mediated by cyclooxygenase products such as $\mathrm{PGE}_{2}$, although indomethacin had no effect on endothelin action in smooth muscle cells (1). From our results, endothelin had a similar inhibitory effect even in the presence of indomethacin, suggesting that cyclooxygenase products such as $\mathrm{PGE}_{2}$ do not mediate the inhibitory action of endothelin. One of the reasons for the difference may be that there are species differences in the effect of $\mathrm{PGE}_{2}$ on AVP-induced cAMP accumulation between rat and rabbit $\mathrm{CCD}(16)$. In the rat $\mathrm{CCD}, \mathrm{PGE}_{2}\left(3 \times 10^{-7} \mathrm{M}\right)$ had no effect on AVP-dependent cAMP accumulation.

Endothelin was shown to stimulate a sustained increase in 1,2-diacylglycerol and protein kinase $C$ activation in bovine aortic smooth muscle cells (17). The endothelin-induced constriction was reversed by the protein kinase $\mathrm{C}$ inhibitor $\mathrm{H}-7$ (18). In our results, the inhibitory effect of endothelin was abolished by H-7, and the effect of endothelin was mimicked by protein kinase $\mathbf{C}$ activator dioctanoyl glycerol, suggesting that protein kinase $C$ activation is involved in the inhibitory effect of endothelin on AVP-dependent cAMP accumulation in the collecting duct. Endothelin is not a toxic substance because the effect of AVP was reversed by $\mathrm{H}-7$ in the presence of endothelin. The role of protein kinase $\mathrm{C}$ in inhibiting AVPdependent cAMP accumulation was also reported in cultured collecting tubular cells (19).

Endothelin increased the urine flow rate despite a decrease in GFR and renal blood flow (RBF) in the rat (4). Another report showed that endothelin increased free water clearance and decreased urinary sodium excretion, urine osmolality, and osmolar clearance in the presence of an unchanged or increased concentration of plasma AVP (5). A decrease in GFR and RBF may be enough to explain the decrease in urinary sodium excretion, but it cannot explain the increase in free water excretion. In collecting ducts, AVP stimulates water permeability by stimulating cAMP generation. Our data demon- 
strating that endothelin inhibits AVP-dependent cAMP accumulation in CCD, OMCD, and IMCD show at least one possible mechanism of the increase in water excretion despite the decrease in GFR and RBF. We could not detect any inhibitory effects of endothelin on AVP-dependent cAMP generation in cTAL and $\mathrm{mTAL}$, although we cannot rule out the possibility that endothelin effects cTAL and mTAL through other pathways.

Endothelin stimulates atrial natriuretic peptide (ANP) in cultured neonatal rat atrial cardiocytes (20) and in conscious dogs. Elevation of plasma ANP concentration may partly explain the increase in water excretion, because ANP has been reported to inhibit the water permeability stimulated by AVP in rabbit CCD (21) and rat IMCD (22). However, ANP increases GFR and Na excretion (23-25), which is the opposite of the effect of endothelin. Therefore, an elevated plasma ANP may not have a major role in the action of endothelin.

In summary, endothelin inhibited AVP-induced cAMP accumulation in CCD, OMCD, and IMCD, but not in CTAL and mTAL. This effect was possibly due to the inhibition of adenylate cyclase activity by protein kinase $\mathrm{C}$ activation, and was independent of phosphodiesterase, $\mathrm{Ca}$ channel, or cyclooxygenase products. On the other hand, endothelin had no effect on PTH-dependent cAMP accumulation in Gl and PCT, and glucagon-, calcitonin-, and isoproterenol-dependent cAMP accumulation in OMCD. Our data suggest that endothelin works to increase water excretion by inhibiting the AVP effect on collecting ducts. This explains, at least partly, the increase in urinary volume in the presence of a decrease in GFR and renal plasma flow caused by endothelin.

\section{Acknowledgments}

We thank Dr. Y. Hirata for his useful suggestions. We gratefully acknowledge the secretarial support of Miss M. Mirokuji.

This work was supported by a grant-in-aid for scientific research in Japan (63570285).

\section{References}

1. Yanagisawa, M., H. Kurihara, S. Kimura, Y. Tomobe, M. Kobayashi, Y. Mitsui, Y. Yazaki, K. Goto, and T. Masaki. 1988. A novel potent vasoconstrictor peptide produced by vascular endothelial cells. Nature (Lond.). 332:411-415.

2. Ando, K., Y. Hirata, M. Shichiri, T. Emori, and F. Marumo 1989. Presence of immunoreactive endothelin in human plasma. FEBS (Fed. Eur. Biochem. Soc.) Lett. 245:164-166.

3. Firth, J. D., P. J. Ratcliffe, A. E. G. Raine, and J. G. G. Ledingham. 1988. Endothelin: an important factor in acute renal failure? Lancet. ii:1179-1181.

4. Badr, K. F., J. J. Murray, M. D. Breyer, K. Takahashi, T. Inagami, and R. C. Harris. 1989. Mesangial cell, glomerular and renal vascular responses to endothelin in the rat kidney. J. Clin. Invest. 83:336-342.

5. Goetz, K. L., B. C. Wang, J. B. Madwed, J. L. Zhu, and R. J. Leadley, Jr. 1988. Cardiovascular, renal, and endocrine responses to intravenous endothelin in conscious dogs. Am. J. Physiol. 255(Regulatory Integrative Comp. Physiol.):R 1064-R1068.

6. Koseki, C., M. Imai, Y. Hirata, M. Yanagisawa, and T. Masaki. 1989. Autoradiographic distribution in rat tissues of binding sites for endothelin: a neuropeptide? Am. J. Physiol. 256(Regulatory Integrative Comp. Physiol. 25):R858-R866.

7. Tomita, K., A. Owada, Y. Iino, N. Yoshiyama, and T. Shiigai. 1987. Effect of vasopressin on $\mathrm{Na}^{+}-\mathrm{K}^{+}$-ATPase activity in rat cortical collecting duct. Am. J. Physiol. 253(Renal Fluid Electrolyte Physiol. 22):F874-F879.
8. Nonoguchi, H., M. A. Knepper, and V. C. Manganiello. 1987. Effects of atrial natriuretic factor on cyclic guanosine monophosphate and cyclic adenosine monophosphate accumulation in microdissected nephron segments from rats. J. Clin. Invest. 79:500-507.

9. Sands, J. M., and M. A. Knepper. 1987. Urea permeability of mammalian inner medullary collecting duct system and papillary surface epithelium. J. Clin. Invest. 79:138-147.

10. Umemura, S., D. Marver, D. D. Smith, and W. A. Pettinger. 1985. $\alpha_{2}$-Adrenoceptors and cellular cAMP levels in single nephron segments from the rat. Am. J. Physiol. 249(Renal Fluid Electrolyte Physiol. 18):F28-F33.

11. Takaichi, K., and K. Kurokawa. 1988. Inhibitory guanosine triphosphate-binding protein-mediated regulation of vasopressin action in isolated single medullary tubules of mouse kidney. J. Clin. Invest. 82:1437-1444.

12. Simonson, M. S., S. Wann, P. Mene, G. R. Dubyak, M. Kester, Y. Nakazato, J. R. Sedor, and M. J. Dunn. 1989. Endothelin stimulates phospholipase $\mathrm{C}, \mathrm{Na} / \mathrm{H}$ exchange, c-fos expression, and mitogenesis in rat mesangial cells. J. Clin. Invest. 83:708-712.

13. Murayama, N., J. L. Werness, E. Kusano, S. Christensen, and T. P. Dousa. 1984. Interaction of forskolin with vasopressin-sensitive cyclic AMP system in renal medullary tubules. J. Cyclic Nucleotide Res. 9:427-433.

14. Kusano, E., N. Murayama, J. L. Werness, S. Christensen, S. Homma, A. N. K. Yusufi, and T. P. Dousa. 1985. Effects of calcium on the vasopressin-sensitive cAMP metabolism in medullary tubules. Am. J. Physiol. 249(Renal Fluid Electrolyte Physiol. 18):F956-F966.

15. Zeidel, M. L., H. Brady, B. Kone, S. Gullans, and B. M. Brenner. 1989. Endothelin, a peptide inhibitor of $\mathrm{Na}^{+}-\mathrm{K}^{+}$-ATPase in intact renal tubular epithelial cells. Am. J. Physiol. 257 (Cell Physiol. 26):C1101-C1107.

16. Chabardes, D., C. Brick-Ghannam, M. Montegut, and S. Siaume-Perez. 1988. Effect of $\mathrm{PGE}_{2}$ and $\alpha$-adrenergic agonists on AVP-dependent cAMP levels in rabbit and rat CCT. Am. J. Physiol. 255(Renal Fluid Electrolyte Physiol. 24):F43-F48.

17. Lee, T.-S., T. Chao, K.-Q. Hu, and G. L. King. 1989. Endothelin stimulates a sustained 1,2-diacylglycerol increase and protein kinase $\mathbf{C}$ activation in bovine aortic smooth muscle cells. Biochem. Biophys. Res. Commun. 162:381-386.

18. Sugiura, M., T. Inagami, G. M. T. Hare, and J. A. Johns. 1989. Endothelin: inhibition by a protein kinase $C$ inhibitor and involvement of phosphoinositols. Biochem. Biophys. Res. Commun. 158:170-176.

19. Dixon, B. S., R. Breckon, C. Burke, and R. Anderson. 1988. Phorbol esters inhibit adenylate cyclase activity in cultured collecting tubular cells. Am. J. Physiol. 254(Cell Physiol. 23):C183-C191.

20. Fukuda, Y., Y. Hirata, H. Yoshimi, T. Kojima, Y. Kobayashi, M. Yanagisawa, and T. Masaki. 1988. Endothelin is a potent secretagogue for atrial natriuretic peptide in cultured rat atrial myocytes. Biochem. Biophys. Res. Commun. 155:167-172.

21. Dillingham, M. A., and R. J. Anderson. 1986. Inhibition of vasopressin action by atrial natriuretic factor. Science (Wash. DC). 231:1572-1573.

22. Nonoguchi, H., J. M. Sands, and M. A. Knepper. 1988. Atrial natriuretic factor inhibits vasopressin-stimulated osmotic water permeability in rat inner medullary collecting duct. J. Clin. Invest. 82:1383-1390.

23. Maack, T., M. J. F. Camargo, H. D. Kleinert, J. H. Laragh, and S. A. Atlas. 1985. Atrial natriuretic factor: structure and functional properties. Kidney Int. 27:607-615.

24. Zeidel, M. L., D. Kikeri, P. Silva, M. Burrowes, and B. M. Brenner. 1988. Atrial natriuretic peptides inhibit conductive sodium uptake by rabbit inner medullary collecting duct cells. J. Clin. Invest. 82:1067-1074.

25. Nonoguchi, H., J. M. Sands, and M. A. Knepper. 1989. ANF inhibits $\mathrm{NaCl}$ and fluid absorption in cortical collecting duct of rat kidney. Am. J. Physiol. 256(Renal Fluid Electrolyte Physiol. 25):F179-F186. 